\title{
Relationship between homocysteine level and diabetic retinopathy: a systematic review and meta-analysis
}

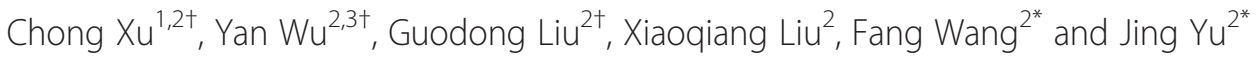

\begin{abstract}
Background: The relationship between homocysteine (Hcy) and diabetic retinopathy (DR) remains unclear to date. Therefore, a systematic review and meta-analysis was performed on the relationship between Hcy level and DR. Methods: Studies were identified by searching PubMed, Embase, and Web of Science databases until 5 May, 2014. Results: A total of 31 studies involving 6,394 participants were included in the meta-analysis. After pooling the data from each included study, the blood Hcy concentration in the DR group was observed to be higher than that in the control group [WMD $=2.55 ; 95 \%$ confidence interval $(C I), 1.70-3.40]$, and diabetes mellitus (DM) patients with hyperhomocysteinemia were at a risk for DR [odds ratio $(\mathrm{OR})=1.93 ; 95 \% \mathrm{Cl}, 1.46-2.53$ ]. Considering the different DM types, hyperhomocysteinemia in T1DM $(\mathrm{OR}=1.83,95 \% \mathrm{Cl}, 1.28-2.62)$ was associated with $\mathrm{DR}$ rather than in T2DM (OR $=1.59,95 \% \mathrm{Cl}, 0.72-3.51)$. Considerable statistical heterogeneity in the overall summary estimates was partly explained by the geographical differences.

Conclusions: Results from this current meta-analysis indicate that hyperhomocysteinemia is a risk factor for DR, especially proliferative DR. Differences between geographical regions were observed in the relationship between hyperhomocysteinemia with T1DM risk. Given the heterogeneous results, the relationship between high Hcy and DR needs further investigation.
\end{abstract}

Virtual Slides: The virtual slide(s) for this article can be found here: http://www.diagnosticpathology.diagnomx.eu/ vs/13000_2014_167

Keywords: Hyperhomocysteinemia, Homocysteine, Diabetic retinopathy (DR)

\section{Background}

Diabetic retinopathy (DR), a common complication of diabetes, is the leading cause of low vision and blindness worldwide [1]. To date, no effective treatment has been found. Therefore, finding new risk factors and biomarkers to prevent the progression of DR is important. A number of risk factors are associated with the incidence of DR, such as blood pressure, blood glucose, glycosylated hemoglobin, blood urea nitrogen, creatinine, and $\beta 2$ microglobulin. However, the risk factors for DR are complicated by many aspects.

\footnotetext{
*Correspondence: dreyemilwang_122@msn.com; dryujing@yahoo.com.cn ${ }^{\dagger}$ Equal contributors

${ }^{2}$ Department of Ophthalmology, Shanghai Tenth People's Hospital, Affiliate of Tongji University School of Medicine, Shanghai 200072, China Full list of author information is available at the end of the article
}

Homocysteine (Hcy) is a sulfur-containing amino acid formed by the demethylation of methionine; it is an emerging risk factor for diabetic nephropathy and cardiovascular disease that has gradually elicited the interest of researchers [2]. These researchers found that the level of Hcy is related to DR, especially proliferative DR $[3,4]$.

However, studies on the relationship between Hcy and DR have reported inconsistent results, and the role of Hcy in the development of DR is not clearly elucidated. Several studies have shown relationships between the blood Hcy level and the prevalence of DR [5,6]. Plasma total Hcy concentration may be a useful biomarker for increased risk of DR in people with type 2 diabetes mellitus (T2DM) [7] and a complication risk indicator in type 1 diabetes mellitus (T1DM) [3]. Moderate hyperhomocysteinemia has been described in T1DM, which may 
be linked between the conditions of mutation in the methylenetetrahydrofolate reductase (MTHFR) gene [8,9]. On the other hand, other studies did not find any relationship between plasma Hcy and different grades of DR on adults with T1DM, except when concomitant nephropathy existed $[10,11]$.

Given the absence of uniform research standards and inconsistency in research results, a meta-analysis of prospective studies on the relationship between Hcy and DR was conducted.

This meta-analysis mainly focused on the following objectives: (1) to review and summarize the epidemiologic evidence on the relationship between hyperhomocysteinemia and risk of DR and (2) to quantify the mechanism of hyperhomocysteinemia and DM relationship according to study characteristics.

\section{Methods}

\section{Search strategy}

The meta-analysis was conducted according to the Preferred Reporting Items for Systematic Reviews and Meta-Analysis guidelines [12].

\section{Study selection}

We searched PubMed, Embase, and Web of Science to retrieve related studies published before May, 2014. Literature search was performed using keywords "homocysteine," "hyperhomocysteinemia," "Hcy," and "homocysteic acid" in combination with "diabetic retinopathy" and "diabetic retinitis." Moreover, the citations of related articles were detected for additional publications. No language or date limitations were set. Corresponding authors of the retrieved articles were contacted for additional information.

\section{Inclusion criteria}

Studies that met the following inclusion criteria were included in this meta-analysis: (1) comparative studies; (2) reported either the prevalence in hyperhomocysteinemia patients and the controls or the concentrations of Hcy in DR and the controls; and (3) provided the value of mean with 95\% confidence intervals (CIs), standard errors or sufficient data to calculate them.

\section{Exclusion criteria}

Studies that met the following inclusion criteria were excluded in this meta-analysis: (1) not for DR research; (2) studies with small sample size (less than 40 cases or control group) and low quality (NOS, less than 6 points) (3) duplicate of previous publication; and articles without available data; (4) the plasma Hcy levels of studies are influenced seriously by pathological factors.

\section{Data extraction}

Data were independently extracted from each included article by two reviewers (C. $\mathrm{Xu}$ and $\mathrm{Y}$. Wu), and all disagreements on eligibility during the extraction were discussed and resolved by the reviewers. The first author, country, year of publication, number of both case and control groups, blood components used for the test, DM type, definition of hyperhomocysteinemia, and matching factors were extracted.

\section{Assessment of methodology quality}

The Newcastle-Ottawa scale (NOS) [13] was adopted for assessing the quality of the included retrospective observational studies. The maximal NOS score was 9 points, and studies $\geq 6$ points were considered to be of relatively higher quality.

\section{Statistical analysis}

This meta-analysis was conducted using the Stata software package (version 11.0; Stata Corp., College Station, TX). A random-effect method was conducted to pool the results together [14]. The pooled odds ratios (ORs) and weighted mean difference (WMD) were measured with 95\% CIs. Both the ORs and WMD were considered statistically significant. The subgroup analyses were performed based on DM type, site, blood component, and study design. Both the $X^{2}$ and $\mathrm{I}^{2}$ tests were used to evaluate the statistical heterogeneity among studies, and the heterogeneity was considered statistical when $\mathrm{P}<0.1$ and $\mathrm{I}^{2} \geq 50 \%$. Metaregression method was used to evaluate the source of heterogeneity.

The sensitivity analysis evaluated the robustness of the results in this study. Two different methods were performed to conduct this analysis. First, the articles were excluded one by one, and then a meta-analysis was again conducted. Second, studies with small sample size (less than 40 participants in either case or control group) and low quality (NOS, less than 6 points) were excluded. To evaluate the potential publication bias, both the funnel plot and the Egger test were performed $[15,16]$.

\section{Results}

\section{Literature search}

Of the 299 articles (72 from PubMed, 147 from Embase, and 80 from Web of Science) identified from database searches, 132 duplicates were excluded. After reviewing the titles and abstract of the 167 remaining articles, 114 articles were excluded and 53 full-text articles were assessed for eligibility. A total of 24 articles (four from duplicated data sources and 20 without available data) were excluded. Moreover, two studies were identified from reference lists. Thirty-one articles were included in this meta-analysis [2-11,17-37], in which nine reported the relationship between hyperhomocysteinemia and risk 
of DR and 27 reported the concentrations in DR and NDR (six studies reported both results).

\section{Characteristics and baseline of the included studies}

Up to 6394 individuals were included in this meta-analysis. A total of 609 cases and 238 controls comprised the comparison between the risk of DR in hyperhomocysteinemia and control groups, and 2070 cases and 3477 controls comprised the comparison between the concentrations of Hcy in DR and NDR groups. The definitions of hyperhomocysteinemia were different in each study, and four of nine studies used $15 \mu \mathrm{mol} / \mathrm{l}$ in the plasma as cut-off. Although the definitions were not the same, no significant differences existed in the definitions. Both plasma and serum were used for the measurement of the concentrations of Hcy in most studies. All of the included articles were retrospective case-control studies. Of the 31 included studies, 4 were conducted in the United States, 11 in Asia, 14 in Europe, and 2 in Oceania. Age and gender were matched in most of the studies. Several studies displayed other comparable factors. Tables 1 and 2 show the characteristics and baselines of the included studies.

\section{Quality assessment}

NOS was used to evaluate the methodological quality of each study because all of the included articles were retrospective case-control studies. Among the 31 studies, six were less than 6 points, and the mean NOS score was $6.45 \pm 1.21$ points. The lowest and the highest scales were 4 points in two studies and 8 points in six studies, respectively.

\section{Efficacy analysis}

\section{Main results}

Figure 1 presents the main results of this current metaanalysis. Patients with hyperhomocysteinemia were at higher risk of developing DR compared with the control group (OR, 1.93; 95\% CI, 1.46 to 2.53 ). The interstudy heterogeneity was not significant $\left(\mathrm{I}^{2}=26.9 \%, \mathrm{P}=0.205\right)$. A higher concentration of Hcy in the blood was observed in the DR group (WMD, 2.55; 95\% CI, 1.70 to 3.40). However, a significant heterogeneity was also detected in the comparison $\left(\mathrm{I}^{2}=98.8 \%, \mathrm{P}<0.001\right)$.

\section{Subgroup analysis}

Subgroup analysis was conducted by DM type, geographic site, blood components, and study designs (Table 3). In the different DM types, T2DM patients with hyperhomocysteinemia did not show higher risk of developing DR (OR, 1.59; 95\% CI, 0.72 to 3.51). However, in both T1DM and mixed-type DM groups, higher incidence rates of DR were detected in the hyperhomocysteinemia group (T1DM: OR, 1.83; 95\% CI, 1.28 to 2.62; Mixed: OR, $1.93 ; 95 \% \mathrm{CI}, 1.46$ to 2.53$)$. In all of the three different DM type groups, the concentration of Hcy was higher in DR groups (T1DM: WMD, 2.5; 95\% CI, 1.04 to 3.97; T2DM: WMD, 2.85; 95\% CI, 1.45 to 4.25; Mixed: WMD, 1.68 ; $95 \% \mathrm{CI}, 0.01$ to 3.35 ).

In the United States and Asia, a higher incidence rate of DR was detected in the hyperhomocysteinemia group (US: OR, 1.9 ; 95\% CI, 1.24 to 2.93; Asia: OR, 2.36; 95\% CI, 1.46 to 3.81 ). However, in Europe, the incidence rate of DR was not higher in the hyperhomocysteinemia group compared with the control group (OR, 1.45; 95\% CI, 0.95 to 2.20). In Asia and Europe, the concentrations of Hcy

Table 1 Characteristics of the studies on the relationship between hyperhomocysyeinemia and risk of diabetic retinopathy

\begin{tabular}{|c|c|c|c|c|c|c|c|}
\hline Source & Country & $\begin{array}{l}\text { No. of } \\
\text { case/control }\end{array}$ & $\begin{array}{l}\text { DM } \\
\text { Type }\end{array}$ & Blood & $\begin{array}{l}\text { Exposure } \\
\text { definition }\end{array}$ & $\begin{array}{l}\text { Study } \\
\text { quality }^{\dagger}\end{array}$ & $\begin{array}{l}\text { Matching/ } \\
\text { comparable* }\end{array}$ \\
\hline Golbahar et al. 2008 [17] & Bahrain & $124 / 130$ & 2 & Plasma & $\begin{array}{l}\text { F: Hcy > } 15 \mu \mathrm{mol} / \mathrm{l} ; \mathrm{M}: \\
\mathrm{Hcy}>12 \mu \mathrm{mol} / \mathrm{l}\end{array}$ & 8 & $1,2,3,4,7,12,13$ \\
\hline Vaccaro et al , 1997 [8] & Japan & $11 / 14$ & 1 & Plasma & $\geq 10 \mu \mathrm{mol} /$ & 6 & $1,2,6,8,9,13$ \\
\hline Hofmann et al., 1998 [18] & France & $26 / 49$ & 1 & Plasma & $\begin{array}{l}\text { Preload }>15.8 \mu \mathrm{mol} / \mathrm{l} \text { or } \\
\text { Postload }>31.1 \mu \mathrm{mol} / \mathrm{l}\end{array}$ & 8 & $1,2,3,4,6,7,9$ \\
\hline Hoogeveen et al., 2000 [5] & Netherlands & $534 / 91$ & 2 & serum & $>16 \mu \mathrm{mol} / \mathrm{l}$ & 7 & $1,2,7,8,9$ \\
\hline Buysschaert et al., 2000 [19] & Belgium & $38 / 84$ & 1 & Plasma & $>15 \mu \mathrm{mol} / \mathrm{l}$ & 7 & $1,2,3,5,6,10,11,12$ \\
\hline Agullo-Ortuno et al., 2002 [3] & Spain & $18 / 71$ & 1,2 & Plasma & $\begin{array}{l}F>13.9 \mu \mathrm{mol} / \mathrm{l} \\
M>15.6 \mu \mathrm{mol} / /\end{array}$ & 5 & $9,10,11,12$ \\
\hline Goldstein et al., 2004 [4] & Israel & $84 / 251$ & NA & Plasma & $>15 \mu \mathrm{mol} / \mathrm{l}$ & 7 & $1,6,14$ \\
\hline de Luis et al., 2005 [20] & Spain & $22 / 133$ & 2 & Plasma & $\geq 15 \mu \mathrm{mol} / \mathrm{l}$ & 6 & $1,6,7,8,9$ \\
\hline Satyanarayana et al., 2011 [21] & US & $141 / 159$ & 2 & Plasma & $>12 \mu \mathrm{mol} / \mathrm{l}$ & 7 & $1,5,9,11$ \\
\hline
\end{tabular}

NA: not available; DM: diabetes mellitus; F: female; M: male; Hcy: homocysteine.

${ }^{\dagger}$ Study quality is evaluated by Newcastle-Ottowa Scale (1-9 stars).

*The matching factors are: (1) age, (2) gender, (3) diabetes duration, (4) diabetes control, (5) hypoglycemia medication, (6) blood pressure, (7) BMI, (8) creatinine, (9) plasma cholesterol, (10) triglyceride, (11) low densitv lipoprotein, (12) high densitv lipoprotein, (13) smoking status, (14) other complications. 
Table 2 Characteristics of the studies on the comparison between the concentrations of homocysteine in the DR and NDR group

\begin{tabular}{|c|c|c|c|c|c|c|c|}
\hline Source & Country & $\begin{array}{l}\text { No. of } \\
\text { case/control }\end{array}$ & $\begin{array}{l}\text { DM } \\
\text { Type }\end{array}$ & $\begin{array}{l}\text { Case group/control } \\
\text { group }\end{array}$ & Blood & $\begin{array}{l}\text { Study } \\
\text { quaility }^{\dagger}\end{array}$ & $\begin{array}{l}\text { Matching/ } \\
\text { comparable* }\end{array}$ \\
\hline Chen, 2010 [22] & China & $88 / 95$ & 2 & DR/normal or DM & Plasma & 6 & 12 \\
\hline Golbahar et al. , 2008 [17] & Bahrain & $124 / 130$ & 2 & DR/DM & Plasma & 8 & $1,2,3,7,8,9,10,11,12,13$ \\
\hline Lim et al., 2012 [23] & Malaysia & $20 / 21$ & 2 & PDR/Normal & Plasma & 5 & 1,2 \\
\hline Hultberg et al., 1991 [24] & Sweden. & $67 / 46$ & 1 & DR/Normal & Plasma & 6 & $1,2,6,13$ \\
\hline Chico et al., 1998 [2] & Spain & $71 / 62$ & 1,2 & DR/DM & Plasma & 8 & $1,2,7,14$ \\
\hline Smulders et al., 1999 [25] & Netherlands & $66 / 71$ & 2 & $\mathrm{DR} / \mathrm{DM}$ & Plasma & 7 & 2 \\
\hline Stabler et al., 1999 [26] & US & $218 / 223$ & 2 & DR/DM & Plasma & 6 & $1,2,14$ \\
\hline Agardh et al., 2000 [10] & Sweden. & $25 / 24$ & 1 & $\mathrm{DR} / \mathrm{DM}$ & Plasma & 7 & $1,2,3,5,6,7$ \\
\hline Vaccaro et al., 2000 [9] & Italy & $30 / 34$ & NA & DR/DM & Plasma & 7 & $1,2,6,13$ \\
\hline Chiarelli et al., 2000 [27] & US & $141 / 117$ & 1 & DR/Normal or DM & Plasma & 8 & $1,2,3,5$ \\
\hline Buysschaert et al., 2001 [28] & France & $24 / 47$ & 1 & $\mathrm{DR} / \mathrm{DM}$ & Plasma & 5 & $1,2,5$ \\
\hline Agullo-Ortuno et al., 2002 [3] & Spain & $18 / 71$ & 1 & DR/DM & Plasma & 6 & $9,10,11,12$ \\
\hline Yang et al., 2002 [29] & China & $16 / 58$ & 2 & DR/Normal or DM & Plasma & 7 & $1,2,6,7$ \\
\hline Abdella et al., 2002 [30] & Kuwait & $145 / 213$ & 2 & DR/DM & Plasma & 6 & $1,3,5,13$ \\
\hline Looker et al., 2003 [31] & US & $102 / 279$ & 2 & $\mathrm{DR} / \mathrm{DM}$ & Serum & 8 & $2,4,5,6,13$ \\
\hline Saeed et al., 2004 [11] & UK & $25 / 23$ & 1 & NPDR/DM & Serum & 7 & $1,2,3,6,7,13$ \\
\hline Goldstein et al., 2004 [4] & Israel & $117 / 218$ & NA & DR/Normal or DM & Plasma & 6 & $1,6,14$ \\
\hline de Luis et al., 2005 [20] & Spain & $22 / 133$ & 2 & $\mathrm{DR} / \mathrm{DM}$ & Plasma & 7 & $1,6,7,8,9$ \\
\hline García-Unzueta et al., 2005 [32] & Spain & $38 / 117$ & 1 & $\mathrm{DR} / \mathrm{DM}$ & Serum & 4 & NA \\
\hline Yücel I, 2004[33] & Turkey & $20 / 30$ & 2 & PDR/Normal & Plasma & 4 & 1,2 \\
\hline Huang et al., 2006 [6] & China & $91 / 370$ & 2 & DR/Normal or DM & Plasma & 7 & $1,2,9,11$ \\
\hline Brazionis et al., 2008 [7] & Australia & $48 / 120$ & 2 & $\mathrm{DR} / \mathrm{DM}$ & Plasma & 8 & $1,2,4,6,10,12,13$ \\
\hline Aydin E, 2008 [34] & Turkey & $39 / 35$ & 2 & DR/Normal or DM & Plasma & 4 & 1,2 \\
\hline Aydemir et al., 2008 [35] & Turkey & $20 / 12$ & 2 & PDR/Normal & Plasma & 5 & 1 \\
\hline Nguyen et al., 2009 [36] & Australia & $278 / 743$ & NA & $\mathrm{DR} / \mathrm{DM}$ & Plasma & 7 & $1,2,7,9,10,13$ \\
\hline Satyanarayana et al., 2011 [21] & US & $150 / 150$ & 2 & DR/Normal or DM & Plasma & 7 & $1,5,9,11$ \\
\hline Cho, 2011 [37] & Korea & $67 / 35$ & 2 & $\mathrm{DR} / \mathrm{DM}$ & Plasma & 6 & $1,6,7,11,12$ \\
\hline
\end{tabular}

NA: not available; DM: diabetes mellitus; DR: diabetic retinopathy; PDR: proliferative diabetic retinopathy.

${ }^{\dagger}$ Study quality is evaluated by Newcastle-Ottowa Scale (1-9 stars).

*The matching factors are: (1) age, (2) gender, (3) diabetes duration, (4) diabetes control, (5) hypoglycemia medication, (6) blood pressure, (7) BMI, (8) creatinine, (9) plasma cholesterol, (10) triglyceride, (11) low densitv lipoprotein, (12) high densitv lipoprotein, (13) smoking status, (14) other complications.

were higher in the DR group compared with the control group (Asia: WMD, 3.43; 95\% CI, 2.59 to 4.28; Europe: WMD, 1.68; $95 \%$ CI, 0.83 to 2.52). However, the concentrations of Hcy in the DR groups were not significantly higher in the US and Oceania (US: WMD, 3.03; $95 \%$ CI, -0.02 to 6.08; Oceania: OR, 0.68 ; $95 \% \mathrm{CI},-0.49$ to 6.08 ).

Four different study designs, namely, DR vs. normal, DR vs. DM, non-proliferative diabetic retinopathy (NPDR) vs. control, and PDR vs. control, were used in the subgroup analysis. A higher incidence rate in hyperhomocysteinemia was detected in all of the subgroups, and a higher concentration of Hcy was detected in the DR group. No inverse results were detected in the subgroup analysis compared with the main results.
The incidence of DR was compared in the two groups (high Hcy and control). Only the subgroup analysis between the DR and the normal group was significantly heterogeneous $\left(\mathrm{I}^{2}=90.9, \mathrm{P}<0.01\right)$. However, most subgroup analyses exhibited significant heterogeneity compared with the Hcy concentrations in DR and NDR. No significant heterogeneity was observed between the DR and the NDR groups, whereas the comparison of Hcy serum was significantly heterogeneous $\left(\mathrm{I}^{2}=51.5, \mathrm{P}=0.13\right)$.

\section{Heterogeneity, sensitivity analysis, and publication bias}

Several outcomes were heterogeneous in this metaanalysis, and the subgroup analysis did not succeed in detecting the source of heterogeneity. In addition, 

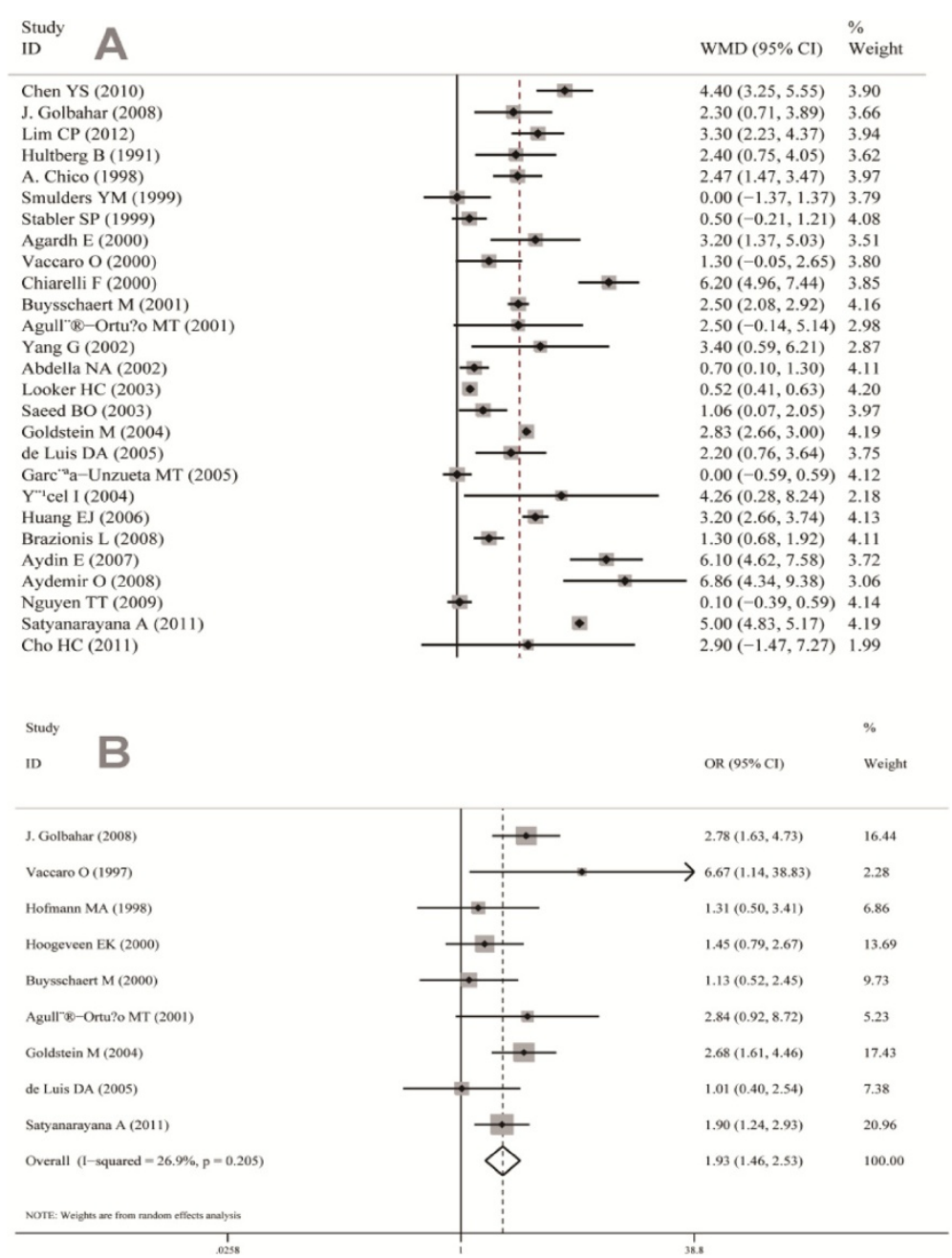

Figure 1 Forest plot of relationship between homocysteine level and diabetic retinopathy. (A) The concentration of Hcy was higher in DR groups than the control group (WMD, 2.55; 95\% Cl, 1.70 to3.40) (B) Diabetes mellitus (DM) patients with hyperhomocysteinemia were at a risk for DR [odds ratio $(\mathrm{OR})=1.93 ; 95 \% \mathrm{Cl}, 1.46-2.53]$.

meta-regression was conducted, and no sources of heterogeneity were detected.

After dropping each study one by one from the included studies, no significant different results were observed. A meta-analysis was conducted after excluding the studies with small sample size (less than 40 participants in either case or control group) and low quality (NOS, less than 6 points). After excluding five studies, a significant relationship was observed between hyperhomocysteinemia and risk of DR (OR, 2.16; 95\%, 1.63 to 2.85). Moreover, after excluding 12 studies, the concentration of Hcy in the DR group was still higher than that in the control group (WMD, 2.16; 95\% CI, 1.12 to 3.40).

Both the funnel plot (Figure 2) and the Egger test showed that no potential publication bias existed in the comparison between the incidence rate of the hyperhomocysteinemia group and the control $(\mathrm{P}=0.07)$ group and the comparison between the concentration of Hcy in $\mathrm{DR}$ and control group $(\mathrm{P}=0.63)$.

\section{Discussion and conclusions}

A large number of studies focused on the relationship between Hcy and retinopathy, but their results were inconsistent. Studies on T1DM reported positive relationships between DR and Hcy [38,39]. Hcy significantly increased in DM patients, and Hcy may be related to longer diabetic duration and DR [6]. Elevated Hcy was also related to increased risk for proliferative retinopathy [31,34]. A high prevalence of retinopathy was found in patients with T2DM who had fasting Hcy concentrations greater than $15 \mu \mathrm{mol} / \mathrm{l}[3,5]$. Hcy may be a predictor of retinopathy in T2DM $[7,9,37]$.

In some studies, no significant correlations existed between plasma Hcy and different grades of DR in patients 
Table 3 Relationship between hyperhomocysteinemia and risk of diabetic retinopathy, and the concentrations of hcy between the DR and NDR groups by subgroup analysis

\begin{tabular}{|c|c|c|c|c|c|c|c|c|c|c|}
\hline \multirow{3}{*}{ Factor } & \multicolumn{5}{|c|}{ Hyperhomocysyeinemia and risk of diabetic retinopathy } & \multicolumn{5}{|c|}{ Homocysteine in DR and NDR } \\
\hline & \multirow{2}{*}{$\begin{array}{l}\text { No. of } \\
\text { studies }\end{array}$} & \multirow[t]{2}{*}{ OR } & \multirow[t]{2}{*}{$95 \% \mathrm{Cl}$} & \multicolumn{2}{|c|}{ Heterogeneity } & \multirow{2}{*}{$\begin{array}{l}\text { No. of } \\
\text { studies }\end{array}$} & \multirow[t]{2}{*}{ WMD } & \multirow[t]{2}{*}{$95 \% \mathrm{Cl}$} & \multicolumn{2}{|c|}{ Heterogeneity } \\
\hline & & & & $P$ & $I^{2}(\%)$ & & & & $P$ & $I^{2}(\%)$ \\
\hline \multicolumn{11}{|l|}{ DM type } \\
\hline T1D & 3 & 1.83 & 1.28 to 2.62 & 0.21 & 33.6 & 7 & 2.5 & 1.04 to 3.97 & 0.00 & 94.0 \\
\hline T2D & 4 & 1.59 & 0.72 to 3.51 & 0.19 & 39.7 & 16 & 2.85 & 1.45 to 4.25 & 0.00 & 99.2 \\
\hline Mixed & 2 & 1.93 & 1.46 to 2.53 & 0.93 & 0.0 & 4 & 1.68 & 0.01 to 3.35 & 0.00 & 97.2 \\
\hline \multicolumn{11}{|l|}{ Site } \\
\hline Unitd Staes & 1 & 1.9 & 1.24 to 2.93 & - & - & 4 & 3.03 & -0.02 to 6.08 & 0.00 & 85.0 \\
\hline Asia & 4 & 2.36 & 1.46 to 3.81 & 0.15 & 44.3 & 11 & 3.43 & 2.59 to 4.28 & 0.00 & 88.6 \\
\hline Europe & 4 & 1.45 & 0.95 to 2.20 & 0.57 & 0.0 & 10 & 1.68 & 0.83 to 2.52 & 0.00 & 85.0 \\
\hline Oceania & - & - & - & - & - & 2 & 0.68 & -0.49 to 6.08 & 0.00 & 99.8 \\
\hline \multicolumn{11}{|l|}{ Blood } \\
\hline Plasma & 8 & 2.01 & 1.49 to 2.72 & 0.20 & 29.0 & 24 & 2.81 & 2.04 to 3.57 & 0.00 & 97.3 \\
\hline Serum & 1 & 1.45 & 0.79 to 2.67 & - & - & 3 & 0.45 & 0.03 to 0.87 & 0.13 & 51.5 \\
\hline \multicolumn{11}{|l|}{ Study design } \\
\hline DR vs normal & 3 & 3.71 & 0.94 to 14.72 & 0.0 & 90.9 & 11 & 5.21 & 3.50 to 6.92 & 0.00 & 99.2 \\
\hline DR vs DM & 9 & 2.02 & 1.52 to 2.68 & 0.33 & 12.1 & 22 & 2.34 & 1.62 to 3.05 & 0.00 & 97.6 \\
\hline NPDR vs control & 2 & 2.66 & 1.74 to 4.06 & 0.88 & 0.0 & 10 & 1.8 & 0.89 to 2.71 & 0.00 & 96.4 \\
\hline PDR vs control & 2 & 2.84 & 1.75 to 4.61 & 0.98 & 0.0 & 12 & 4.53 & 3.16 to 5.90 & 0.00 & 91.6 \\
\hline
\end{tabular}

-: no data; DM: diabetes mellitus; T1D: type 1 diabetes mellitus; T2D: type 2 diabetes mellitus; DR: diabetic retinopathy; PDR: proliferative diabetic retinopathy; NPDR: nonproliferative diabetic retinopathy; hcy: homocysteinemia.

with T1DM, except when a concomitant nephropathy was present $[10,11,30,36]$. Hyperhomocysteinemia is probably caused by early nephropathy rather than a result of the diabetic process itself $[2,11,40]$. The reasons for these inconsistencies may be due, in part, to differences in the study sample (e.g., groups with different diabetic duration), study design, definitions of DR (e.g., clinical versus photograph grading), and failure in some studies to make adequate adjustments for traditional risk factors.

A comprehensive and quantitative summary was lacking on the relationship between Hcy and DR. Therefore, a meta-analysis was conducted to assess the relationship

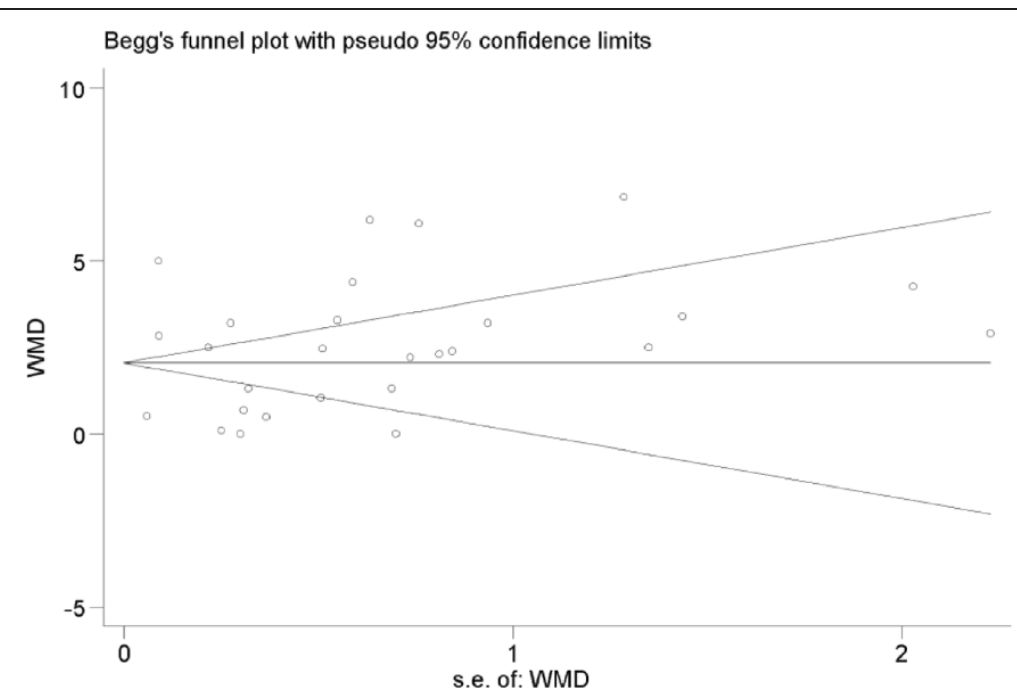

Figure 2 Funnel plot of the included studies. Funnel plot of the WMD vs the standard error of the log WMD for studies evaluating homocysteine level and diabetic retinopathy. 
between Hcy and DR. Based on the meta-analysis of the DR groups compared with the normal or DM patients, Hcy concentration in the blood was higher than in the control. These results are the same as those of the PDR groups compared with the control, especially in Asia and Europe. No significant differences were observed in Australia and USA. These findings may be associated with research heterogeneity or the district biases. The different research methods and the sensitivity to detect retinopathy by fundus photography or misclassification of retinopathy may result in district bias.

Plasma Hcy levels are influenced by environmental and genetic factors [41], as well as by age, sex, duration of diabetes, smoking habits, body mass index, metabolic control, creatinine clearance, impaired renal function, vitamin status, and blood pressure $[11,21,28,42]$. The kidney has an important function in maintaining Hcy levels. The enzyme MTHFR is active in the kidney, and impairment of renal function can lead to hyperhomocysteinemia [11].

Many studies excluded serious pathology state of research groups, and different research groups matched for these factors, which could influence plasma Hcy levels. Therefore, we believe that hyperhomocysteinemia may be a potential risk factor for DR patients [31].

A higher incidence of DR exists in diabetic patients with hyperhomocysteinemia. According to the different DM types, a significant difference in T1DM group is observed, whereas no significant difference is detected in T2DM group. Given all the differences, the incidence of
DR in hyperhomocysteinemia cases is higher than in the control, except in Europe. Although most relationships are not significant, a high homocysteinemia is common in the relationship with the incidence of DR, especially with PDR (Table 3). To understand the significance of the results in Table 3, heterogeneity and subgroup analyses were analyzed. In the comparison between the incidence of DR in different levels of plasma Hcy groups, only the DR groups compared with normal groups were significantly heterogeneous $\left(\mathrm{I}^{2}=90.9, \mathrm{P}<0.01\right)$. This result may due to the different study designs with different methodological qualities.

The pathogenesis of hyperhomocysteinemia in the development of DR may accelerate cell injury (including oxidative stress and impaired generation of nitric oxide) and proliferate smooth muscle cells to alter vasomotor activity $[43,44]$. Cell injury at the level of the retinal capillary may contribute to the development of DR $[8,18,45,46]$. The relationship between PDR and plasma Hcy levels may be related to $\mathrm{C} 677 \mathrm{~T}$ mutation in the gene coding for the MTHFR $[8,9,17,47]$.

A few studies demonstrated that vitreous hyperhomocysteine is related to DR because of the loss of bloodretinal barrier permeability. This result may augment the diffusion of Hcy into the vitreous and the changes in vascular permeability $[35,48]$. Therefore, an elevated Hcy level in the vitreous may be important in the pathogenesis of PDR [23].

Given the numerous factors influencing the development and progression of DR, some of them remain unknown. We believe that hyperhomocysteinemia is

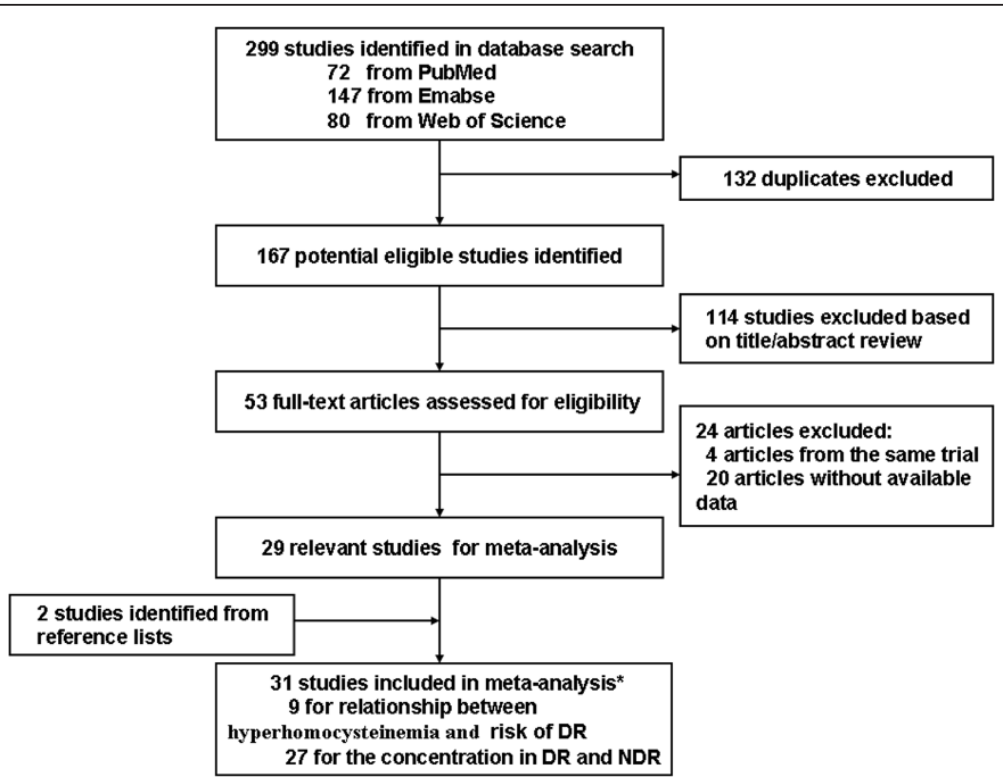

Figure 3 Flow diagram showing the identification of relevant studies in the meta-analysis. The initial 299 articles were identified and after 133 uplicates and 114 unrelated articles were excluded. A total of 53 full-text articles were assessed for eligibility. Twenty-four articles were excluded from and 2 articles from reviewing the reference lists of the related articles were included. In final, 31 articles were included in this meta-analysis. 
another contributing factor to DR, especially to the severity of retinopathy independent of other risk factors [4].

The most significant conclusion that can be obtained from the data in Figures 1,2 and 3 is the influence of concentration of plasma Hcy level on the incidence of DR and the progression of this microvascular complication of the retina, particularly in T1DM in Asia and the United States.

Some limitations of this meta-analysis are as follows. First, the included studies are not randomized controlled trials, and thus, may hold potential bias. Second, several outcomes were quite heterogeneous in this meta-analysis, and the subgroup analysis was not successful in detecting the source of heterogeneity. Moreover, we cannot obtain a possible threshold between the blood Hcy level and the separate degrees of DR because of the limited number of subjects with retinopathy and the different study designs.

The risk factors for DR are complicated by many aspects. Using Insulin may increase the risk of diabetic retinopathy [49], However, hyperhomocysteinemia correlates with insulin resistance and it could play a role in the higher risk of cardiovascular disease in obesity [50]. Diabetic retinopathy (DR) was earlier recognized as a vascular disease, but nowadays, it is considered as a neurovascular disorder. hyperhomocysteinemia plays important role in causation of retinal ganglionic cell apoptosis in diabetic patients [51]. Moreover, gene-gene and gene-environment interactions should also be considered in future analysis.PPAR 2 Pro12Ala polymorphism is not a risk factor for developing T2D diabetic nephropathy [52]. The association of plasma Hcy level and MTHFR gene polymorphism also be widely studied [53]. MTHFR polymorphism is shown to be associated with lipid metabolism in the elderly women [54].And this consistence to our study that Hcy level is related to MTHFR (coded by C667Tgene) polymorphism and may be the risk of diabetic complications.

All these meta-analysis are very significant to show the relationship between the different risk factors with diabetic retinopathy and other diabetic Complications. But our meta show the relationship between Hcy and different aspect of DR deeply.

Hcy may be a potential useful biomarker in assessing the microvascular risk in diabetes, and hyperhomocysteinemia is a potential risk factor for DR, especially PDR. This result may help DM patients in obtaining an instructive management to prevent the progression of DR because the plasma Hcy level can be substantially lowered with folic acid supplementation. High Hcy on DR will result in increasing attention to the study of gene C667T polymorphism and related prevention and treatment methods. In addition, considering the limitation of this study, larger studies should be considered and conducted to validate the current meta-analysis.
Abbreviation

Hcy: Homocysteine; DR: Diabetic retinopathy.

Competing interests

The authors declare that they have no competing interests.

\section{Authors' contributions}

$C X, Y W, G D L$ and FW provided the conduction of the whole project, CX, YW, $\mathrm{GDL} X \mathrm{XQ}$, and $J Y$ reviewed the the literature and statistical datas, CX, YW, GDL and XQL drafted the manuscript; FW and JY contributed to revise the manuscript. All authors read and approved the final manuscript.

\section{Author details}

${ }^{1}$ Department of Opthalmology, Nanshan Maternity \& child healthcare hospital of Shenzhen, Shenzhen, China. ${ }^{2}$ Department of Ophthalmology, Shanghai Tenth People's Hospital, Affiliate of Tongji University School of Medicine, Shanghai 200072, China. ${ }^{3}$ Department of First Clinical Medical College, Nanjing Medical University, Nanjing, Jiangsu, China.

Received: 26 June 2014 Accepted: 16 August 2014

Published online: 26 September 2014

\section{References}

1. Congdon NG, Friedman DS, Lietman T: Important causes of visual impairment in the world today. JAMA 2003, 290:2057-2060.

2. Chico A, Perez A, Cordoba A, Arcelus R, Carreras G, de Leiva A, Gonzalez-Sastre F, Blanco-Vaca F: Plasma homocysteine is related to albumin excretion rate in patients with diabetes mellitus: a new link between diabetic nephropathy and cardiovascular disease? Diabetologia 1998, 41:684-693.

3. Agullo-Ortuno MT, Albaladejo MD, Parra S, Rodriguez-Manotas M, Fenollar M, Ruiz-Espejo F, Tebar J, Martinez P: Plasmatic homocysteine concentration and its relationship with complications associated to diabetes mellitus. Clin Chim Acta 2002, 326:105-112.

4. Goldstein M, Leibovitch I, Yeffimov I, Gavendo S, Sela BA, Loewenstein A Hyperhomocysteinemia in patients with diabetes mellitus with and without diabetic retinopathy. Eye (Lond) 2004, 18:460-465

5. Hoogeveen EK, Kostense PJ, Eysink PE, Polak BC, Beks PJ, Jakobs C, Dekker JM, Nijpels G, Heine RJ, Bouter LM, Stehouwer CD: Hyperhomocysteinemia is associated with the presence of retinopathy in type 2 diabetes mellitus: the Hoorn study. Arch Intern Med 2000, 160:2984-2990.

6. Huang EJ, Kuo WW, Chen YJ, Chen TH, Chang MH, Lu MC, Tzang BS, Hsu $\mathrm{HH}$, Huang CY, Lee SD: Homocysteine and other biochemical parameters in type 2 diabetes mellitus with different diabetic duration or diabetic retinopathy. Clin Chim Acta 2006, 366:293-298.

7. Brazionis L, Rowley K Sr, Itsiopoulos C, Harper CA, O'Dea K: Homocysteine and diabetic retinopathy. Diabetes Care 2008, 31:50-56.

8. Vaccaro O, Ingrosso D, Rivellese A, Greco G, Riccardi G: Moderate hyperhomocysteinaemia and retinopathy in insulin-dependent diabetes. Lancet 1997, 349:1102-1103.

9. Vaccaro O, Perna AF, Mancini FP, Cuomo V, Sacco M, Tufano A, Rivellese AA, Ingrosso D, Riccardi G: Plasma homocysteine and its determinants in diabetic retinopathy. Diabetes Care 2000, 23:1026-1027.

10. Agardh E, Hultberg B, Agardh CD: Severe retinopathy in type 1 diabetic patients is not related to the level of plasma homocysteine. Scand J Clin Lab Invest 2000, 60:169-174.

11. Saeed BO, Nixon SJ, White AJ, Summerfield GP, Skillen AW, Weaver JU: Fasting homocysteine levels in adults with type 1 diabetes and retinopathy. Clin Chim Acta 2004, 341:27-32.

12. Moher D, Liberati A, Tetzlaff J, Altman DG: Preferred reporting items for systematic reviews and meta-analyses: the PRISMA statement. BMJ 2009, 339:b2535.

13. Stang A: Critical evaluation of the Newcastle-Ottawa scale for the assessment of the quality of nonrandomized studies in meta-analyses. Eur J Epidemiol 2010, 25:603-605

14. Gagne JJ, Power MC: Anti-inflammatory drugs and risk of Parkinson disease: a meta-analysis. Neurology 2010, 74:995-1002.

15. Egger M, Davey Smith G, Schneider M, Minder C: Bias in meta-analysis detected by a simple, graphical test. BMJ 1997, 315:629-634.

16. Begg CB, Mazumdar M: Operating characteristics of a rank correlation test for publication bias. Biometrics 1994, 50:1088-1101. 
17. Golbahar J, Rahimi M, Tabei MB, Aminzadeh MA: Clinical risk factors and association of hyperhomocysteinemia with diabetic retinopathy in Iranian type 2 diabetes patients: a cross-sectional study from Shiraz, Southern Iran. Diabetes Metab Syndr Clin Res Rev 2008, 2:192-201.

18. Hofmann MA, Kohl B, Zumbach MS, Borcea V, Bierhaus A, Henkels M, Amiral J, Schmidt AM, Fiehn W, Ziegler R, Wahl P, Nawroth PP: Hyperhomocyst(e)inemia and endothelial dysfunction in IDDM. Diabetes Care 1998, 21:841-848.

19. Buysschaert M, Dramais AS, Wallemacq PE, Hermans MP: Hyperhomocysteinemia in type 2 diabetes: relationship to macroangiopathy, nephropathy, and insulin resistance. Diabetes Care 2000, 23:1816-1822.

20. de Luis DA, Fernandez N, Arranz ML, Aller R, Izaola O, Romero E: Total homocysteine levels relation with chronic complications of diabetes, body composition, and other cardiovascular risk factors in a population of patients with diabetes mellitus type 2. J Diabetes Complications 2005, 19:42-46.

21. Satyanarayana A, Balakrishna N, Pitla S, Reddy PY, Mudili S, Lopamudra P, Suryanarayana P, Viswanath K, Ayyagari R, Reddy GB: Status of B-vitamins and homocysteine in diabetic retinopathy: association with vitamin-B12 deficiency and hyperhomocysteinemia. PLoS One 2011, 6:e26747.

22. Chen YS: Contents changes and correlations between Hcy and Cystatin C in patients with diabetic retinopathy in type 2 diabetes mellitus. Int J Ophthal 2010, 10:2107-2110.

23. Lim CP, Loo AV, Khaw KW, Sthaneshwar P, Khang TF, Hassan M, Subrayan V: Plasma, aqueous and vitreous homocysteine levels in proliferative diabetic retinopathy. Br J Ophthalmol 2012, 96:704-707.

24. Hultberg B, Agardh E, Andersson A, Brattstrom L, Isaksson A, Israelsson B, Agardh CD: Increased levels of plasma homocysteine are associated with nephropathy, but not severe retinopathy in type 1 diabetes mellitus. Scand J Clin Lab Invest 1991, 51:277-282.

25. Smulders YM, Rakic M, Slaats EH, Treskes M, Sijbrands EJ, Odekerken DA, Stehouwer CD, Silberbusch J: Fasting and post-methionine homocysteine levels in NIDDM: determinants and correlations with retinopathy, albuminuria, and cardiovascular disease. Diabetes Care 1999, 22:125-132

26. Stabler SP, Estacio R, Jeffers BW, Cohen JA, Allen RH, Schrier RW: Total homocysteine is associated with nephropathy in non-insulin-dependent diabetes mellitus. Metabolism 1999, 48:1096-1101.

27. Chiarelli F, Pomilio M, Mohn A, Tumini S, Vanelli M, Morgese G, Spagnoli A, Verrotti A: Homocysteine levels during fasting and after methionine loading in adolescents with diabetic retinopathy and nephropathy. J Pediatr 2000, 137:386-392.

28. Buysschaert M, Jamart J, Dramais AS, Wallemacq P, Hermans MP: Micro- and macrovascular complications and hyperhomocysteinaemia in type 1 diabetic patients. Diabetes Metab 2001, 27:655-659.

29. Yang G, Lu J, Pan C: The impact of plasma homocysteine level on development of retinopathy in type 2 diabetes mellitus. Zhonghua Nei Ke Za Zhi 2002, 41:34-38.

30. Abdella NA, Mojiminiyi OA, Akanji AO, Moussa MA: Associations of plasma homocysteine concentration in subjects with type 2 diabetes mellitus. Acta Diabetol 2002, 39:183-190.

31. Looker HC, Fagot-Campagna A, Gunter EW, Pfeiffer CM, Narayan KM, Knowler WC, Hanson RL: Homocysteine as a risk factor for nephropathy and retinopathy in type 2 diabetes. Diabetologia 2003, 46:766-772.

32. Garcia-Unzueta MT, Berrazueta JR, Pesquera C, Obaya S, Fernandez MD, Sedano C, Amado JA: Levels of plasma total adrenomedullin are related with two acute phase inflammatory reactants (fibrinogen and sialic acid) but not with markers of endothelial dysfunction in type 1 diabetes adrenomedullin and vascular risk factors in type 1 DM. J Diabetes Complications 2005, 19:147-154

33. Yücel I, Yücel G, Müftüoglu F: Plasma homocysteine levels in noninsulindependent diabetes mellitus with retinopathy and neovascular glaucoma. Int Ophthalmol 2004, 25(4):201-205

34. Aydin E, Demir HD, Ozyurt H, Etikan I: Association of plasma homocysteine and macular edema in type 2 diabetes mellitus. Eur J Ophthalmol 2008, 18:226-232.

35. Aydemir O, Turkcuoglu P, Guler M, Celiker U, Ustundag B, Yilmaz T, Metin K: Plasma and vitreous homocysteine concentrations in patients with proliferative diabetic retinopathy. Retina 2008, 28:741-743.

36. Nguyen TT, Alibrahim E, Islam FM, Klein R, Klein BE, Cotch MF, Shea S, Wong TY: Inflammatory, hemostatic, and other novel biomarkers for diabetic retinopathy: the multi-ethnic study of atherosclerosis. Diabetes Care 2009, 32:1704-1709.
37. Cho HC: The relationship among homocysteine, bilirubin, and diabetic retinopathy. Diabetes Metab J 2011, 35:595-601.

38. Vaccaro O, Perna AF, Mancini FP, lovine C, Cuomo V, Sacco M, Tufano A, Rivellese AA, Ingrosso D, Riccardi G: Plasma homocysteine and microvascular complications in type 1 diabetes. Nutr Metab Cardiovasc Dis 2000, 10:297-304.

39. Agardh CD, Agardh E, Andersson A, Hultberg B: Lack of association between plasma homocysteine levels and microangiopathy in type 1 diabetes mellitus. Scand J Clin Lab Invest 1994, 54:637-641.

40. Cronin CC, MCPartlin JM, Barry DG, Ferriss JB, Scott JM, Weir DG: Plasma homocysteine concentrations in patients with type 1 diabetes. Diabetes Care 1998, 21:1843-1847

41. Socha MW, Polakowska MJ, Socha-Urbanek K, Fiedor P: Hyperhomocysteinemia as a risk factor for cardiovascular diseases: the association of hyperhomocysteinemia with diabetes mellitus and renal transplant recipients. Ann Transplant 1999, 4:11-19.

42. Sindrey M, Marshall TL, Naish P: Quantitative assessment of the effects of platelet depletion in the autologous phase of nephrotoxic serum nephritis. Clin Exp Immunol 1979, 36:90-96.

43. Starkebaum G, Harlan JM: Endothelial cell injury due to copper-catalyzed hydrogen peroxide generation from homocysteine. J Clin Invest 1986, 77:1370-1376.

44. Chen C, Conklin BS, Ren Z, Zhong DS: Homocysteine decreases endothelium-dependent vasorelaxation in porcine arteries. J Surg Res 2002, 102:22-30.

45. Blacker HR: Talking to patients. Nurs Times 1976, 72:1212-1214.

46. Hofmann MA, Kohl B, Zumbach MS, Borcea V, Bierhaus A, Henkels M, Amiral J, Fiehn W, Ziegler R, Wahl P, Nawroth PP: Hyperhomocyst(e)inemia and endothelial dysfunction in IDDM. Diabetes Care 1997, 20:1880-1886.

47. Russo GT, Di Benedetto A, Magazzu D, Giandalia A, Giorda CB, lentile R, Previti M, Di Cesare E, Cucinotta D: Mild hyperhomocysteinemia, C677T polymorphism on methylenetetrahydrofolate reductase gene and the risk of macroangiopathy in type 2 diabetes: a prospective study. Acta Diabetol 2011, 48:95-101.

48. Coral K, Angayarkanni N, Gomathy N, Bharathselvi M, Pukhraj R, Rupak R: Homocysteine levels in the vitreous of proliferative diabetic retinopathy and rhegmatogenous retinal detachment: its modulating role on lysyl oxidase. Invest Ophthalmol Vis Sci 2009, 50:3607-3612.

49. Zhao C, Wang W, Xu D, Li H, Li M, Wang F: Insulin and risk of diabetic retinopathy in patients with type 2 diabetes mellitus: data from a meta-analysis of seven cohort studies. Diagn Pathol 2014, 9:130.

50. Tang L, Ye H, Hong Q, Chen F, Wang Q, Xu L, Bu S, Liu Q, Ye M, Wang DW Mai $Y$, Duan S: Meta-analyses between 18 candidate genetic markers and overweight/obesity. Diagn Pathol 2014, 9:56.

51. Ganapathy PS, White RE, Ha Y: The role of N-methyl-D-aspartate receptor activation in homocysteine-induced death of retinal ganglion cells. Invest Ophthalmol Vis Sci 2011, 52:5515-5524.

52. Wang L, Teng Z, Cai S, Wang D, Zhao X, Yu K: The association between the PPARgamma2 Pro12Ala polymorphism and nephropathy susceptibility in type 2 diabetes: a meta-analysis based on 9,176 subjects. Diagn Pathol 2013, 8:118.

53. Zappacosta B, Graziano M, Persichilli S, Di Castelnuovo A, Mastroiacovo P lacoviello L: 5,10-Methylenetetrahydrofolate reductase (MTHFR) C677T and $\mathrm{A} 1298 \mathrm{C}$ polymorphisms: genotype frequency and association with homocysteine and folate levels in middle-southern Italian adults. Cell Biochem Funct 2014, 32:1-4.

54. Chmurzynska A, Malinowska AM, Twardowska-Rajewska J, Gawecki J: Elderly women: homocysteine reduction by short-term folic acid supplementation resulting in increased glucose concentrations and affecting lipid metabolism (C677T MTHFR polymorphism). Nutrition 2013, 29:841-844.

\section{doi:10.1186/s13000-014-0167-y}

Cite this article as: Xu et al:: Relationship between homocysteine level and diabetic retinopathy: a systematic review and meta-analysis. Diagnostic Pathology 2014 9:167. 